\section{Língua Brasileira de Sinais e formação} de professores: uma análise de conteúdos e estratégias metodológicas no ensino de Libras L1

Brazilian sign language and teacher training: an analysis of contents and methodological strategies in Libras (L1) teaching

Andréa Michiles Lemos (D) $\mathbf{0}$ *, Renata Castelo Peixoto (D) $\mathbf{0}$

RESUMO: Com a oficialização da Língua Brasileira de Sinais - Libras - por meio da lei 10.436/02 e do decreto 5626/05, surge a necessidade da formação em nível superior de professores dessa língua. A partir dessa exigência, a Universidade Federal de Santa Catarina criou o curso semipresencial de Letras/Libras. O presente trabalho tem como objetivo refletir sobre o ensino da Libras como L1, enfocando as estratégias de ensino e os conteúdos propostos por alunos-estagiários desse curso no polo da Universidade Federal do Ceará. Foram analisados os projetos de trabalho, os relatórios de estágio, além das aulas de Libras ministradas. As reflexóes construídas nesse trabalho dialogam com autores, tais como: Antunes (2003; 2007) e Possenti (1996) e nos apontam alguns resultados, tais como: a) os estagiários selecionaram conteúdos gramaticais com enfoque descritivo em detrimento de um enfoque gramatical reflexivo e às situaçôes de compreensão e produção de gêneros textuais em língua de sinais; b) a atuação docente revela certo engessamento quanto ao domínio e aplicação do conteúdo; e c) significativa interferência da Língua Portuguesa (L2) nas situações didáticas. Esses resultados nos sugerem que a recência do ensino de Libras pode levar os alunos-estagiários a buscarem fundamentos para organizar a sua ação docente.

PALAVRAS-CHAVE: Ensino; Libras; Primeira língua; Estratégias de ensino.

ABSTRACT: With the officialization of Brazilian Sign Language Libras - by Law 10.436/02 and Decree 5626/05, the need for training for teachers of that language at undergraduation level arises.

From this requirement on, the Federal University of Santa Catarina created the partial distance course Letras Libras. The present work aims to reflect on Libras teaching as L1, focusing on teaching strategies and the contents proposed by student-trainees of this course at the Federal University of Ceará pole. We analyzed the work projects, internship reports, in addition to the Libras classes that were taught. The reflections built into this work dialogue with authors such as

\begin{tabular}{|l|l|l|l} 
Revista Linguagem em Foco & Fortaleza, CE & v. 12 n. 1 & ISSN 2674-8266
\end{tabular}

\section{Linguagęm Foco Revista do Programa de Pós-Graduação em Linguística Aplicada da UECE}

Mestre em Linguística. Professora do Departamento de Educação (DEDUC) do Instituto Federal de Educaçáo, Ciência e Tecnologia do Ceará (IFCE); Campus Fortaleza/Ce; email: andrea.lemos@ifce.edu.br.

Doutora em Educação Brasileira. Professora do Departamento de Letras Libras e Estudos Surdos (DELLES) da Universidade Federal do Ceará (UFC); Centro de Humanidades - Forateza/Ce; e-mail: renatycp@ gmail.com.

Distribuído sobre

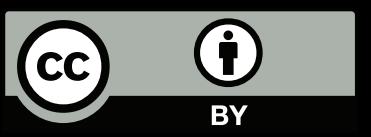


Antunes (2003; 2007) and Possenti (1996) and show us some results, such as: a) the trainees selected grammatical contents with a descriptive focus rather than a reflexive focus on grammar and situations of sign language textual genres comprehension and production, b) teacher performance reveals certain inflexibility concerning the domain and appliance of the content, and c) significant interference of the Portuguese (L2) in teaching situations. These results suggest that the Libras teaching recency can lead student-trainees to seek a basis for organizing their teaching activities.

KEYWORDS: Education; Libras; First language; Teaching strategies.

\section{INTRODUÇÃO}

A reflexão aqui apresentada tem como ponto de partida a experiência das autoras de acompanhamento através da tutoria do estágio em ensino de Libras como primeira língua (L1) realizado no âmbito do curso de graduação a distância em Letras Libras da Universidade Federal de Santa Catarina (UFSC) em parceria com a Universidade Federal do Ceará (UFC).

A implementação dos cursos de Letras Libras foi uma iniciativa pioneira da UFSC ${ }^{1}$ que através da modalidade de ensino a distância e da parceria com 16 instituiçóes de ensino superior, espalhadas por todo o Brasil, deu início no ano de 2006 ao processo de formação de professores de Língua Brasileira de Sinais (Libras). Tal formação constitui em uma das exigências do decreto no 5626 de 2005 que traz ainda outras deliberaçóes para a efetivação do reconhecimento legal da Língua Brasileira de Sinais - iniciado com a lei no 10.436 de 2002 - como uma língua legítima nacional e que deve, portanto, ser assegurada aos cidadãos surdos, especialmente nos espaços públicos (BRASIL, 2002).

A citada lei e sua regulamentação através do decreto 5626/05, embora cheguem tão tardiamente, representam uma importante conquista para a legitimação da condição bilíngue dos surdos brasileiros e para o fortalecimento de um - novo - discurso sobre a surdez. Tal discurso, que vem ganhando força nas últimas décadas, nega a perspectiva que define a surdez como patologia, como manifestação de um ouvido doente em um sujeito que precisa ser reabilitado à suposta homogeneidade da "normal" condição de ouvir e falar.

Esse novo discurso, que relata a surdez como minoria linguística, como especificidade cultural e como diferença que marca positivamente a identidade de quem a tem, vem sendo gestado especialmente desde as três últimas décadas ${ }^{2}$, como consequência das lutas dos movimentos surdos organizados e de várias pesquisas nas mais diferentes áreas (Educação, Linguística, Psicologia) que vêm identificando na língua de sinais um elemento fundamental para assegurar o desenvolvimento e a aprendizagem, além de facilitar a inclusão social do surdo.

Outro importante alavancador desse novo discurso foi o fracasso generalizado das práticas de ensino orientadas por uma visão oralista. Tais práticas, predominantes entre o final do século XIX e o final do século XX, transformaram as escolas em clínicas fonoterápicas e os surdos em sujeitos "deficientes" $1 \quad$ O curso de licenciatura em Letras Libras proposto pela UFSC em 2006 foi o primeiro em toda a América Latina.

2 Certamente há, desde o advento do Gestualismo de L'Epée no século XVIII, elementos favoráveis para o reconhecimento dessa positividade da surdez e das línguas de sinais, mas entendemos que é apenas no final do século passado que esses elementos ganham força e representatividade suficientes através da Filosofia Bilíngue de Educação e da concepção sócio-antropológica de surdez.

\begin{tabular}{c|c|c|c}
\hline Revista Linguagem em Foco & Fortaleza, CE & v. $12 \mathrm{n} .1$ & ISSN 2674-8266 \\
\hline
\end{tabular}




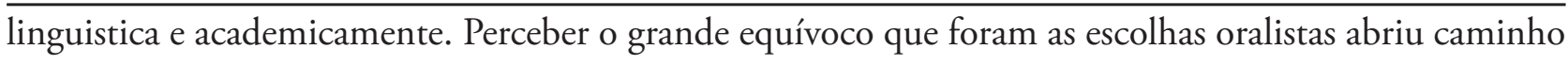
para que as línguas de sinais fossem - novamente - problematizadas pela escola, pela sociedade e pelas mais diversas ciências. Aqui um importante destaque deve ser feito para os estudos linguísticos, especialmente para a pesquisa na década de 1960 do americano William Stokoe que, analisando a língua de sinais americana, identifica os parâmetros fonológicos (ou quirológicos), morfológicos e sintáticos de organização dessa língua, colocando-a (e indiretamente as demais línguas de sinais), pela primeira vez, em um lugar semelhante ao ocupado pelas línguas orais (STOKOE, 1960).

O reconhecimento linguístico iniciado na década de $1960^{3}$ e o reconhecimento legal das últimas décadas abrem caminho para que lutemos por um reconhecimento social e uma transformação efetiva na escola e na sociedade brasileira. A disseminação da Língua de Sinais e da Cultura Surda é, portanto, por um lado, reflexo dessas conquistas, mas, por outro, é condição para que esse reconhecimento social vire uma realidade cada vez mais concreta e presente. Portanto, o ensino de Libras, seja como primeira língua nas escolas para surdos, seja como segunda língua (L2) para ouvintes nas escolas regulares, universidades, igrejas e associações, assim como a formação de professores que garantam a qualidade desse ensino são açôes fundamentais que devem ser asseguradas de agora em diante.

Como partes envolvidas nessas primeiras experiências de formação de professores de Libras, acreditamos na imperiosa necessidade de refletir sobre elas. Toda prática pedagógica somente evolui à medida que podemos revê-la, pensá-la, discuti-la e confrontá-la. O estágio, como processo final da formação básica e momento privilegiado de articulação entre teoria e prática nos deu uma excelente oportunidade para refletir sobre o ensino de Libras. Tentamos nos debruçar em especial sobre as estratégias de ensino de Libras como L1 e os conteúdos selecionados pelos alunos-estagiários que acompanhamos no último semestre do curso no ano de $2010^{4}$. Entender os desafios e as problemáticas que marcaram essa experiência pioneira é, a nosso ver, o primeiro passo para superá-las e assim contribuir para a construção de práticas de ensino mais eficazes e com uma formação de professores de Libras ainda melhor.

\section{CONSIDERAÇÓES SOBRE O ENSINO DE LIBRAS L1}

A licenciatura em Letras Libras oferecida pela UFSC propôs três áreas de atuação para a realização do estágio: Libras como primeira língua, Literatura surda (ambas para alunos surdos) e Libras como segunda língua (L2) (para alunos ouvintes). Optamos por fazer uma análise e reflexão focada na primeira modalidade (L1) por que identificamos nela muitos desafios.

O ensino de Libras, em geral, é bastante recente e há apenas um pouco mais de 25 anos se ensina Libras no Brasil ${ }^{5}$, sendo privilegiado o ensino da língua para os ouvintes. A predileção histórica pelo ensino de Libras como L2 provavelmente se justifica pela necessidade de divulgar a língua - até então marginalizada em todos os âmbitos - e aproximá-la da comunidade ouvinte, estabelecendo possibilidades inéditas de comunicação.

3 No Brasil, estudos semelhantes com a Língua Brasileira de Sinais (Libras) vão acontecer a partir da década de 1980 com a linguista Lucinda Ferreira Brito.

$4 \quad$ Embora esse artigo traga dados analisados de uma experiência vivenciada no ano de 2010, a sua relevância se justifica por trazer reflexóes importantes para a formação de professores de Libras como L1 para surdos, além do que os cursos de Letras Libras são uma realidade recente no Brasil, portanto é necessário refletir sobre as experiências de estágio para fomentar melhorias.

5 Referimo-nos aqui ao ensino formal, institucionalizado (associaçôes, igrejas, escolas).

Revista Linguagem em Foco
Fortaleza, CE v. 12 n. 1

ISSN 2674-8266 
A ênfase no ensino de Libras como L2 parece ter mobilizado as associações e federaçóes de surdos a proporem também formação de instrutores e produção de material didático nessa área, negligenciando a área de ensino de Libras L1 ${ }^{6}$. Hipotetizamos, juntamente a Basso, Strobel e Masutti (2009), que essa formação e essa experiência acumulada em ensino de Libras L2 vêm repercutindo nas práticas de ensino de Libras L1.

Há pouco tempo, a Libras vem entrando nas escolas de surdos como objeto de estudo 7 . Com o decreto 5626/05, a partir de 2005 passa a ser assegurado ao surdo o direito de aprender sua língua, convocando, assim, as escolas a transformarem a Libras em disciplina acadêmica.

O acolhimento à língua de sinais, mesmo nas instituiçóes especializadas, corresponde, ainda hoje, mais ao reconhecimento dela como instrumento de comunicação do que como conteúdo curricular. A evidência disso pode ser percebida quando analisamos a carga horária de ensino e planejamento destinados à disciplina de Libras (L1) que, em muitas instituiçôes, é ainda inferior à carga horária das demais disciplinas do currículo.

Soma-se, a isso o fato de que, no âmbito federal, não há ainda orientaçóes e nem exigências específicas quanto à carga horária ou mesmo quanto aos conteúdos, objetivos ou metodologias no que diz respeito ao ensino de Libras $^{8}$ L1. A falta de parâmetros dificulta a implementação dessa disciplina, deixando o ensino da Libras a mercê da boa vontade dos gestores, que em sua maioria, são ouvintes e sem formação relacionada à surdez e a Libras. Certamente, a construção de um currículo de Libras num país de tamanha extensão territorial - e consequente variação cultural - deve passar pelas particularidades de cada região, comunidade e escola, formando, ao final, propostas variadas, mas, é preciso também assegurar elementos mínimos comuns.

As propostas curriculares e os programas de ensino de Libras para surdos devem, como afirmam Basso, Strobel e Masutti (2009), considerar a heterogeneidade do seu público alvo e "organizar-se de forma flexível e aberta, sendo constantemente reavaliadas" (p.24). As experiências dos surdos com a

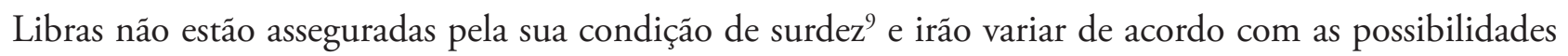
familiares e escolares anteriores de acesso ao sinais, assim, é bastante recorrente encontrar alunos, em uma mesma sala, com níveis bem diferentes em relação à língua de sinais. Níveis esses que Basso, Strobel e Masutti (2009) classificam em três: nível básico, intermediário e avançado ${ }^{10}$.

Além disso, assim como acontece com qualquer outra situação de ensino de língua "materna", a idade e a etapa de escolaridade dos alunos também devem determinar formas diferenciadas de trabalho com a língua. É esperado que crianças da Educação Infantil e do primeiro segmento do ensino fundamental vivenciem aulas de Libras com foco na aquisição da língua e com metodologias que privilegiem o uso 6 A Federação Nacional de Educação e Integração de Surdos (FENEIS) oferece cursos para a formação de instrutores e monitores de Libras - para ouvintes e, em 2001, em parceria com o Ministério da Educação ofereceu cursos para a formação de agentes multiplicadores para o ensino desta língua. A FENEIS há mais de 30 anos realiza cursos de Libras para ouvintes.

7 Certamente, enquanto veículo de comunicação e expressão dos surdos sempre esteve presente. Mesmo no auge da "ditadura oralista", quando os alunos eram proibidos de sinalizarem, havia língua de sinais no ambiente escolar, ainda que às escondidas (nos banheiros e corredores) durante os intervalos.

8 Há diretrizes para o ensino de Libras L1 em alguns estados do país - como, por exemplo, no estado de Sáo Paulo cujas diretrizes para o ensino de Libras datam de 2008. No Ceará não temos ainda nenhum documento correlato.

9 Lembramos que mais de $90 \%$ dos surdos provêm de lares ouvintes, que têm uma língua oral como primeira língua e que, geralmente, não conhecem a língua de sinais local.

10 Para compreender melhor esses níveis ver Basso; Strobel; Masutti (2009).

\begin{tabular}{c|c|c|c}
\hline Revista Linguagem em Foco & Fortaleza, CE & v. $12 \mathrm{n} .1$ & ISSN 2674-8266 \\
\hline
\end{tabular}


"natural" 11 da mesma, enquanto alunos maiores do Fundamental II e Ensino Médio podem debruçarse sobre a língua de forma mais reflexiva, investigando aspectos estruturais e de organização gramatical.

Entendemos que, assim como acontece com qualquer outra língua que é objeto de ensino, fazse necessário refletir sobre os parâmetros que norteiam, justificam e viabilizam esse ensino. Assim, problematizamos o que consideramos serem os principais elementos organizadores do ensino de Libras: os conteúdos, os objetivos e as metodologias/estratégias empregadas. Para isso, assumimos nesta pesquisa uma concepçáo sociointeracionista, na qual a língua é percebida como um processo dinâmico, uma construção fruto da dialogia, que como diz Antunes (2003) "só existe para promover a interação entre as pessoas" (p.41).

Começando com os "objetivos" entendemos, assim como Basso, Strobel e Massuti (2009), que o ensino da Libras em qualquer nível escolar deve visar o desenvolvimento da competência comunicativa dos alunos surdos. Coerente com uma perspectiva interacionista de língua, o trabalho realizado na escola deve estar em sintonia com as mais diferentes demandas de uso da língua que o aluno tem fora da escola. Compreender e produzir discurso em língua de sinais - na modalidade sinalizada ou escrita - em situaçóes de formalidade ou coloquiais, em situaçóes de trabalho ou lazer, assegurando um uso apropriado a cada contexto e a cada interlocutor deve ser o principal propósito do ensino de Libras.

Faz-se pertinente evocar, nesse momento, os Parâmetros Curriculares Nacionais (PCNs) para o Ensino de Língua Portuguesa (BRASIL, 1998) que apresentam objetivos semelhantes. Diz o documento: "espera-se que os alunos adquiram progressivamente uma competência em relação à linguagem que lhes possibilite resolver problemas da vida cotidiana, ter acesso a bens culturais e alcançar a participaçáo plena no mundo letrado" (BRASIL, 1998, p.41). Evocamos os PCNs de língua portuguesa pois, ainda que se trate de outra língua, entendemos que ocupa, para a maioria dos brasileiros, um lugar semelhante ao que a língua de sinais ocupa para o surdo, nos permitindo estender os objetivos de ensino dos PCNs para o ensino de Libras como língua materna.

A competência comunicativa em língua de sinais, assim como acontece com as línguas orais precisa abarcar os usos escrito e sinalizado ${ }^{12}$. Nesse sentido, voltamos a estabelecer o paralelo entre língua de sinais e língua portuguesa, buscando em Antunes (2003), as orientações para a escolha dos conteúdos a serem trabalhados no ensino de Libras como língua materna. A autora, assim como outros pesquisadores, identifica quatro principais áreas de intervenção: a oralidade (que, nesse caso, trata-se da sinalização), a leitura, a escrita e a gramática ou estudo da língua.

\section{EXPERIÊNCIA DO ESTÁGIO DO CURSO DE LETRAS LIBRAS}

\subsection{ORGANIZAÇÃO DA DISCIPLINA DE ESTÁGIO ${ }^{13}$}

A disciplina de estágio em ensino de Libras L1 - do curso de Letras/Libras - foi organizada em

11 Nesse sentido mencionamos a experiência de ensino de Libras L1 relatadas por Lodi e Luciano (2009) em que as aulas aconteciam através da contação de histórias e da brinquedoteca, através de brincadeiras e interaçôes contextualizadas e lúdicas. Observações semelhantes são feitas por Quadros (2000) quando discute a alfabetização em língua de sinais.

12 Nas línguas orais seria a própria oralidade.

13 Salientamos que a descrição que fazemos acerca da organização do estágio refere-se ao estágio realizado no polo da UFC e mais especificamente à organização do estágio dos alunos acompanhados pelas professoras-tutoras que são também as autoras desse artigo. 
cinco principais momentos, a saber: preparação teórica, leitura crítica de campo, elaboração dos projetos de trabalho, realização das aulas práticas e análise dos dados.

No primeiro momento (preparaçáo teórica), os alunos estagiários surdos - sob a orientação da professora da disciplina e dos professores-tutores do curso - fizeram um estudo teórico para compreender o que é o estágio e suas implicaçôes para a formação do professor, para conhecer a prática docente à luz da legislação e de teóricos como Pimenta (2002 e 2004) e Maciel (2004). Esses autores, entre outros, defendem o estágio em sala de aula não apenas enquanto prática de ensino, na qual as atividades de estágio ficam reduzidas a "técnicas a ser empregadas em sala de aula" (PIMENTA, 2004, p. 37), mas também enquanto espaço de pesquisa. A pesquisa no estágio potencializa a prática docente e o ensino, o professor é convidado a buscar formas de superar a mesmice na reprodução dos conhecimentos.

Para Maciel (2004), a formação do professor pautada na ação investigativa propicia a construção de um professor reflexivo que constrói conhecimentos a partir da prática de ensino. Nessa perspectiva, a disciplina de estágio foi elaborada com o intuito de propiciar aos alunos estagiários uma oportunidade de pensarem o momento do estágio também como um lugar destinado à pesquisa, daí a importância dessa disciplina ter sido disposta em cinco momentos. A vivência de cada etapa foi importante para a construção desse futuro profissional reflexivo.

Ainda nesse primeiro momento, os alunos estagiários foram convidados a compreender o que é e para que serve um Projeto Político Pedagógico (PPP); o que é um projeto de trabalho para a organização da ação docente e como elaborá-lo.

No segundo momento, os estagiários foram à escola para realizar a leitura crítica do campo. $\mathrm{O}$ objetivo dessa etapa era não somente analisar os espaços, como o ambiente físico da escola, as salas de aula, além do PPP, corpo docente e administrativo, mas, também, analisar os espaços sociais, culturais, econômicos e políticos nos quais a comunidade escolar está envolvida. Ou seja, nesse momento, os estagiários deveriam perceber como a realidade global na qual a escola está inserida pode influenciar na prática docente. Por essa razão, a leitura crítica de campo precisa ser "um ato reflexivo que se pauta na investigação" (RANGEL; LIMA; SILVA, 2010, p.32). A investigação de campo foi norteada por perguntas problematizadoras que ajudaram na realização da leitura crítica. A etapa seguinte foi elaborar os projetos de trabalho condizentes com a realidade constatada na escola.

Isso demandou, por parte dos estagiários, uma análise da leitura de campo para a proposição das temáticas a serem abordadas em sala de aula. Os projetos de trabalho, em sua maioria, foram elaborados em duplas para turmas do Ensino Fundamental II.

O passo seguinte, após a elaboração do projeto, foi a realização das aulas, momento em que o estagiário deveria colocar em prática tudo o que foi estudado e aprendido. Apesar de os projetos de trabalho terem sido elaborados em duplas, os alunos estagiários entraram em sala de aula separadamente, cada um em uma sala de aula da mesma série, por exemplo, o aluno A ministrou aulas na $7^{\text {a }} \mathrm{A}$ e o aluno

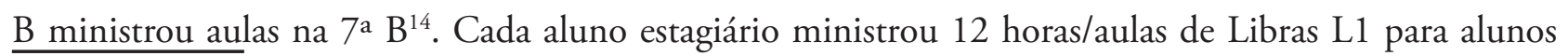
14 Os alunos elaboraram os projetos de trabalho em duplas, mas os realizaram separados em virtude do tempo. Essa quarta etapa iniciou-se quase ao final do semestre e não havia tempo hábil para que cada aluno estagiário da dupla cumprisse com a carga horária de aula exigida. Além disso a organização e distribuição da carga horária das disciplinas de Libras L1, na escola, eram de $4 \mathrm{~h}$ semanais distribuídas em dois dias da semana. Caso a dupla de estagiários ficasse na mesma turma, seria necessária carga horária dobrada, o que a escola considerou muito tempo de afastamento do professor regente da sala de aula. 
surdos, compreendendo o ensino da língua em si e a Literatura Surda. Da carga horária ministrada pelos estagiários, os professores-tutores acompanharam e observaram ${ }^{15}$, em média, de uma a duas aulas de Libras L1.

O quinto e último momento da disciplina de estágio foi a análise dos dados. Nesse momento, os estagiários fizeram uma análise de suas aulas - que foram registradas em diário de campo ou filmadas por eles - e desenvolveram o relatório final de estágio. Este relatório foi composto por todo o processo da disciplina, sendo suas partes constituintes: a leitura crítica de campo, os projetos de trabalho (fundamentação teórica) e a análise crítica reflexiva dos dados coletados em sala de aula, além da estrutura básica de um trabalho acadêmico: capa, folha de rosto, folha de aprovação, dedicatória, sumário, resumo e introdução. Para finalizar esse processo, cada aluno apresentou para a turma, em sistemática de seminários, a sua experiência de docência no estágio.

\subsection{SISTEMÁTICA METODOLÓGICA DA PRESENTE PESQUISA}

Nosso trabalho foi feito com base no acompanhamento de 12 dos 48 alunos do curso de Letras/ Libras - Polo UFC. A escolha desses alunos se deu por serem os alunos que foram acompanhados por nós, autoras deste artigo, durante a disciplina de estágio: os outros estagiários que foram acompanhados por outros tutores não fizeram parte dessa reflexão.

Para a realização desta pesquisa, elaboramos uma sistemática de trabalho pautada em três etapas: 1) análise dos relatórios de estágio; 2) análise das aulas observadas e 3) confronto do relatório de estágio com a prática de sala de aula. Nossa reflexão foi orientada e fundamentada nos aportes teóricos do ensino de Língua Materna e no ensino de Libras L1. Para nossa análise trouxemos autores como Antunes (2003, 2009) e Travaglia (1997).

Inicialmente, analisamos partes do relatório de estágio produzido pelo estagiário (leitura crítica do campo, a fundamentação teórica desenvolvida, os planos de aula e a análise de dados). Nessa primeira etapa, fizemos anotaçóes referentes aos relatos dos alunos estagiários quanto à observação de campo, aos aspectos teóricos mencionados na fundamentação teórica e quanto aos conteúdos programados para as aulas.

No segundo momento da análise, nós retomamos as nossas anotaçóes feitas no momento de observação das aulas ministradas pelos estagiários, a fim de verificar os principais aspectos percebidos por nós no momento da observação in loco da aula; em seguida, assistimos aos vídeos das aulas observadas - as que foram filmadas - com a intenção de rever a "atuação" do estagiário, com o intuito de fazermos uma análise mais percuciente e precisa dos aspectos percebidos.

A terceira etapa foi o momento do confronto entre o que nós encontramos nos relatórios de estágio e o que encontramos na prática da sala de aula dos estagiários.

Em seguida, aportadas no que diz a literatura sobre o ensino de Libras L1 e sobre o ensino de língua materna, nós fizemos uma reflexão sobre o ensino de Libras L1 e a prática de estágio desenvolvida no curso de Letras Libras, no polo da UFC.

$15 \quad$ Grande parte das aulas acompanhadas foi filmada.

\begin{tabular}{c|c|c|c}
\hline Revista Linguagem em Foco & Fortaleza, CE & v. 12 n. 1 & ISSN 2674-8266 \\
\hline
\end{tabular}




\subsection{PRINCIPAIS ASPECTOS OBSERVADOS NOS DADOS DA PESQUISA}

Nesta seção, realizamos algumas discussóes em relação à observação que fizemos das aulas dos estagiários, aos projetos e relatórios de estágio. Em nossa análise, percebemos alguns aspectos que eram comuns a mais de um aluno estagiário; decidimos, então, salientá-los e os sistematizamos em sete principais pontos.

No primeiro aspecto, que chamamos de relação com $L 2^{16}$, observamos que os estagiários tinham uma forte e consciente preocupação com o aprendizado da língua portuguesa por parte dos alunos surdos, mesmo não sendo esse o objetivo do estágio em Libras L1. Essa preocupaçáo ficou evidente na escolha e na abordagem dos conteúdos selecionados para a realização das aulas do estágio. Confirmamos a nossa hipótese quando, na fala de alguns estagiários - durante o seminário de apresentação do seu relatório de estágio -, eles afirmaram que os alunos surdos deveriam aprender o português para ter garantido o direito à educação bilíngue. Alguns exemplos de exploração dos conteúdos são: a utilização de sites para trabalhar com a escrita em português, o uso da soletração digital em Libras, mas com o objetivo de ensinar as palavras do português.

Além do exposto acima, observamos, neste ponto, relação com L2, já que os estagiários fizeram uma confusão entre o que seria conteúdo a ser estudado em Libras L1 e o que seria conteúdo do ensino do português enquanto L2 para surdos. A confusão entre conteúdos foi facilmente detectada quando, por exemplo, o estagiário se propôs a trabalhar os verbos em Libras, mas, ao abordar o assunto trabalhou com os verbos de terminação AR, ER e IR e suas conjugações temporais de presente, passado e futuro da língua portuguesa. Na sequência dos trabalhos, ainda com o mesmo conteúdo sobre verbos, o estagiário pediu aos alunos que falassem exemplos de sinais que fossem verbos e, sem delimitar as línguas em questão ou dar maiores explicaçôes, apresentou aos alunos alguns verbos da língua de sinais.

Ainda tratando desse primeiro aspecto observado, percebemos que, mesmo a proposta do estágio sendo o ensino de Libras L1, os estagiários prepararam e utilizaram para a realização de suas aulas, materiais e estratégias de ensino de Libras enquanto L2, ou seja, do ensino de Libras para ouvintes. Entendemos que alguns fatores contribuíram para que isso acontecesse, entre eles estão a incipiência das práticas pedagógicas no ensino de Libras L1, a influência de uma prática pedagógica, anterior, de ensino de Libras L2 (como instrutores), a escassez de materiais didáticos para o ensino de Libras L1 e a falta de orientaçóes curriculares para esse ensino.

Para finalizar e exemplificar esse aspecto observado, mostramos, a seguir duas atividades propostas pelos estagiários: 


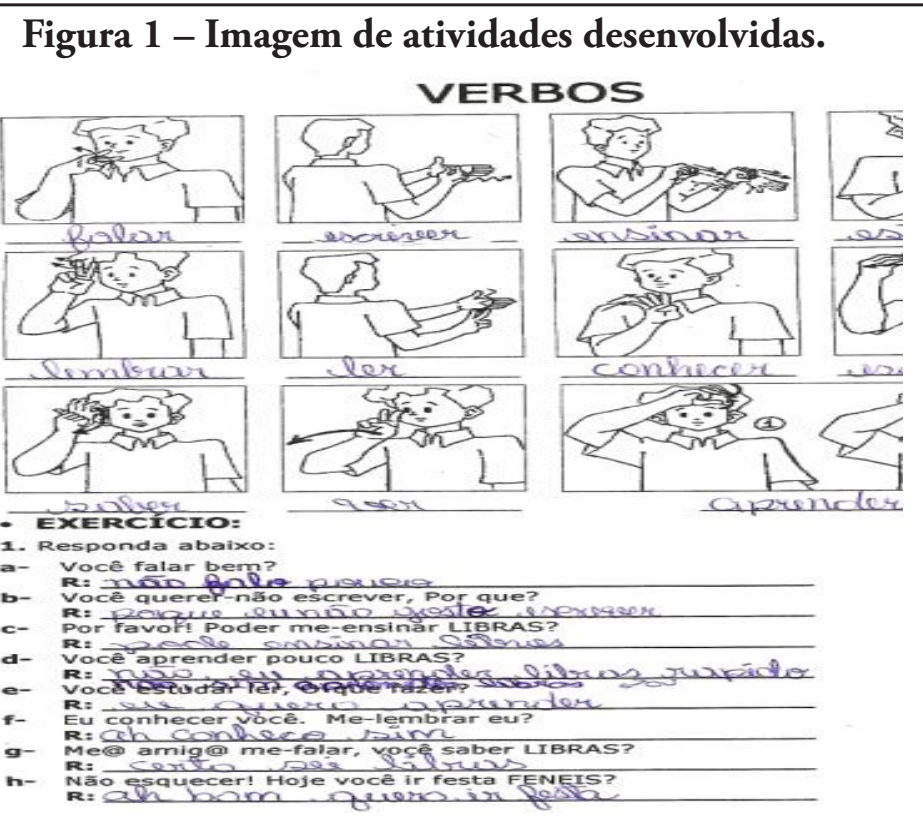

Fonte: Atividades desenvolvidas em sala.

Como verificamos acima, as duas atividades propostas podem ser tipos de atividades que são aplicadas ao ensino de Libras L2. Atividades que utilizam a língua portuguesa, como suporte, para o aprendizado da língua de sinais. Porém, podem também ser uma tentativa do professor-estagiário em promover uma 'escrita dos sinais' em forma de glosas ${ }^{17}$. Na primeira atividade, o foco é dar nomes aos sinais apresentados; e, na segunda, o foco é a escrita em português (ou em glosas), o aluno deve escrever em resposta as perguntas para depois sinalizar o texto, essas estratégias são utilizadas nos cursos de Libras L2. Talvez de forma inconsciente, o foco das atividades é levar o aluno a escrever em português (ou em glosas) e não ao uso da 'oralidade' da língua de sinais e as questôes de ensino da língua que envolve essa oralidade.

Como dissemos anteriormente, acreditamos que a falta de diretrizes e de materiais para o ensino de Libras L1, além da influência de uma prática anterior de ensino de Libras L2, sejam fatores preponderantes para essa 'mistura' de metodologias. Apesar de esses estagiários terem tido uma formação acadêmica para o ensino de Libras L1, a criação dessa disciplina na grade curricular escolar é recente e ainda há muito para ser discutido e amadurecido para a 'solidificação' da prática docente do professor de Libras, tanto no que diz respeito a práticas pedagógicas, quanto a materiais didáticos.

Para Silveira (2007), a construção do currículo de Libras propiciaria o empoderamento dos surdos, pois, uma vez solidificado esse currículo - além dos conteúdos e uma prática pedagógica comprometida a partir da postura política do professor de Libras - inserido na comunidade surda -, os laços de identidade surdo-surdo seriam fortalecidos.

Outro aspecto que observamos foi o de aulas predominantemente expositivas. Este ponto aponta para uma contradição entre as reflexôes feitas pelos estagiários em seus relatórios finais de estágio e as práticas por nós observadas em sala de aula. Os estagiários demonstraram, em seus relatórios, valorizar positivamente a interação e a participação dos alunos nas aulas, fizeram severas críticas às práticas da cópia e da repetição de conteúdos em detrimento da reflexão e da elaboração, mas, essa reflexão não se

\begin{tabular}{c|c|c|c}
\hline Revista Linguagem em Foco & Fortaleza, CE & v. 12 n. 1 & ISSN 2674-8266 \\
\hline
\end{tabular}


concretizou em suas aulas - não nas aulas observadas. Ao contrário, os alunos foram levados, através da metodologia de trabalho proposta, à repetição e à cópia de conteúdos. Nessa abordagem com o predomínio de aulas expositivas, o aluno foi convidado a se manifestar apenas de maneira direcionada e sem refletir sobre a atividade desenvolvida.

Em consonância com a prática de aulas expositivas, podemos observar um terceiro aspecto que foi pouca reflexão e pouco acolhimento sobre os 'erros' e sobre respostas diferentes do esperado, ou seja, em situaçôes de respostas, dadas pelos alunos, diferenciadas do esperado pelo estagiário, esse último não convidava o aluno à reflexão, mas apenas o informava de seu 'erro' e dava a resposta 'correta', geralmente, dentro de uma visão tradicional do conteúdo, mantendo o aprendizado em um nível superficial.

Esses aspectos nos chamaram a atenção e nos levaram à reflexão: será que esse excesso de exposição nas aulas seria decorrente do pouco tempo de aula observada e da preocupação do estagiário em mostrar para nós que dominava o conteúdo? Ou será que os estagiários estariam reproduzindo experiências vivenciadas em sua vida acadêmica?

Outro aspecto intrigante observado foi o predominio de projetos com temas de gramática com abordagem tradicional. Os estagiários, em quase sua totalidade, propuseram projetos de trabalho com aulas exclusivamente voltadas para o estudo da gramática, com proposta de abordagem tradicional e sem apresentar contextualizaçôes que justificassem o estudo daquele ponto gramatical. A seguir apresentamos uma tabela elencando os principais temas eleitos pelos estagiários, constantes nos projetos de trabalho.

Quadro 1 - Conteúdos propostos nos projetos de trabalho

\begin{tabular}{|l|l|}
\hline \multicolumn{2}{|l|}{ CONTEÚDOS DAS AULAS DE L1 } \\
\hline Tecnologias e meios de comunicação & Uso do espaço / apontação \\
\hline Origem da Libras / Lei da Libras & Morfologia \\
\hline Escola de surdos e bilinguismo & Pares mínimos (distinção quanto a CM) \\
\hline Derivação & Parâmetros da formação do sinal \\
\hline $\begin{array}{l}\text { Pesquisas em línguas de sinais e a } \\
\text { importância de saber os elementos } \\
\text { gramaticais }\end{array}$ & $\begin{array}{l}\text { Fonologia da Libras (fonemas, alofones, } \\
\text { CM) }\end{array}$ \\
\hline Configuraçães de mãos (CM) & Alfabeto manual \\
\hline $\begin{array}{l}\text { Empréstimos linguísticos (sinais rítmicos } \\
\text { e sinais com inicialização) }\end{array}$ & $\begin{array}{l}\text { Grupo de CM na formação de } \\
\text { classificadores }\end{array}$ \\
\hline Tipos de Classificadores & Incorporação de negação \\
\hline Papel da iconicidade e abstração & Antônimo \\
\hline Vocabulário & Expressão Não-Manuais \\
\hline Língua, linguagem & Movimento e locação de classificadores \\
\hline Língua de sinais & Tipos de verbos na Libras \\
\hline Gramática (da Libras) & Classes gramaticais e suas funções \\
\hline
\end{tabular}

Fonte: Elaborado pelas autoras.

Como podemos observar na tabela acima, houve na escolha dos temas um predomínio de

Revista Linguagem em Foco

Fortaleza, CE

v. 12 n. 1

ISSN 2674-8266 
conteúdos ligados à fonologia da Libras, especialmente sobre Configuração de Máos (CM); outro tema muito abordado foi o uso de classificadores, mas também, predominantemente, vinculado às CM's, o que pode ser uma influência da experiência prévia desses alunos-estagiários como instrutores de Libras L2. Observamos que o assunto sobre as Configuraçôes de Mãos apareceu quase que na totalidade dos conteúdos elencados nos projetos dos estagiários, mesmo quando o tema indicado não favorecia trabalhar esse tipo de conteúdo.

Denominamos o quinto aspecto observado de uso de gêneros textuais. $\mathrm{Na}$ discussão sobre o ensino de língua, defendemos a importância de se trabalhar com gêneros textuais ${ }^{18}$ orais/sinalizados e escritos desde os anos iniciais do ensino fundamental. De acordo com Costa e Araújo (2007), o objetivo da escola é propiciar uma aprendizagem reflexiva, na qual o aluno possa dominar as práticas discursivas e ter um bom desenvolvimento em qualquer situação comunicativa. "Exige-se uma escola que trabalhe a funcionalidade da língua, permitindo-lhes o uso das muitas práticas comunicativas, a partir dos vários tipos de discursos presentes no mundo contemporâneo" (COSTA e ARAÚJO, 2007).

$\mathrm{Na}$ análise que fizemos do estágio, constatamos que alguns estagiários indicaram em suas discussóes teóricas a preocupação ou a consciência da importância de se trabalhar o acesso a diferentes funçóes e uso da língua, em outras palavras, de se trabalhar a competência comunicativa do aluno. Por outro lado, ao analisarmos os projetos desenvolvidos, percebemos que poucos estagiários contemplaram uma abordagem com foco nos gêneros textuais em seus projetos de ensino de Libras L1; e aqueles que tentaram trabalhar com a perspectiva do gênero textual, o utilizaram apenas como pretexto para a veiculação de conteúdos ou como ilustração de imagens, mas em momento nenhum - das aulas observadas e dos projetos de trabalho - foram explorados os aspectos de função e estrutura dos gêneros apresentados. É possível que algum estagiário tenha feito ajustes e tenha trabalhado com gêneros em suas aulas, mas não está registrado nos documentos analisados.

Mais uma vez, fomos convidadas à reflexão: eles reconhecem a importância de trabalhar as diferentes funçóes e usos da língua, mas não concretizam a exploração de gêneros textuais em suas propostas didáticas. Por quê? E porque os gêneros textuais em língua de sinais não foram explorados? Acreditamos que a inexistência de materiais didáticos, ou mesmo de estudos, voltados para o ensino de Libras por meio do uso de gêneros textuais possam ter influenciado a não escolha do estagiário em trabalhar por esse viés. Alguns dos gêneros que apareceram foram: histórias em quadrinhos, site de busca, site de rede social, documentário e apenas um gênero sinalizado, um documentário/filme.

O sexto aspecto observado foi dos 04 campos do ensino de lingua: a oralidade (sinalização), a leitura, a escrita (sinais escritos) e a gramática. $\mathrm{O}$ ensino de língua materna tem privilegiado as metodologias de ensino que consideram o trabalho com os gêneros textuais. Esse ensino deve ter como objetivo desenvolver a competência comunicativa do aluno; para isso precisa priorizar as situaçóes reais de uso da língua vivenciada por esse aluno. É necessário contemplar as quatro áreas de ensino de língua: a oralidade, a leitura, a escrita e a gramática, áreas igualmente importantes para o bom domínio de uma língua.

De acordo com Massuti, Basso e Strobel (2009, p. 31), no ensino da língua de sinais como língua materna, a "oralidade" em sinais deveria ser o campo mais explorado em sala de aula, uma vez que os

18 Para saber mais sobre gêneros discursivos ou textuais, ver Bakhtin (1997) e Marcuschi (2002).

\begin{tabular}{c|c|c|c}
\hline Revista Linguagem em Foco & Fortaleza, CE & v. 12 n. 1 & ISSN 2674-8266 \\
\hline
\end{tabular}


alunos surdos - na grande maioria das vezes - chegam à escola com pouco conhecimento acerca de sua própria língua ${ }^{19}$. Trabalhar os gêneros textuais com os alunos surdos propiciaria a eles uma melhor compreensão e expressão em língua de sinais nos diversos contextos de uso da língua. Esperávamos, na realidade do estágio, encontrar aulas mais dialógicas, metodologias mais voltadas ao uso da língua de sinais que aproveitassem os três principais, de acordo com Quadros (2006), instrumentos de ensino da língua de sinais: a produção de literatura em sinais, a elaboração de materiais escritos em sinais e o registro em sinais (vídeos e escritos).

Ao contrário do que esperávamos, e já evidenciado no quadro de conteúdos acima, houve um predomínio quase que absoluto do quarto campo de ensino (gramática) em detrimento aos outros três campos (sinalização, leitura e escrita dos sinais), não havendo nenhum estagiário que se propusesse a trabalhar com os sinais escritos (leitura e escrita). Os conteúdos gramaticais foram abordados de maneira muito mais prescritiva do que levando em consideração as características da língua de sinais que, de acordo com Quadros (2006):

[...] é uma língua espacial-visual e existem muitas formas criativas (grifo nosso) de explorá-la. Configuração de mãos, movimentos, expressões faciais gramaticais, localizaçōes, movimentos do corpo, espaço de sinalização, classificadores são alguns dos recursos discursivos que tal língua oferece para serem explorados durante o desenvolvimento da criança surda e que devem ser explorados para um processo de alfabetizaçáo com êxito (QUADROS, 2006, p. 26).

Apesar de aparecer nos conteúdos elencados, alguns temas que poderiam ser explorados levando em consideração a modalidade visual e espacial da língua ficaram relegados ao ensino da norma de funcionamento da língua sem levar em consideração atividades linguísticas, epilinguísticas e metalinguísticas para uma melhor compreensão do funcionamento e uso da língua.

Novamente, voltamos a refletir: por que houve uma abordagem de ensino táo gramatical e dissociada dos gêneros e usos reais da língua? Fomos convidadas a pensar em alguns fatores que poderiam ser contribuidores para essa "escolha” dos estagiários, tais quais elencamos agora:

- Influência do histórico do ensino de português para surdos que muitos surdos vivenciaram;

- Influência da experiência discente do estagiário nos ensinos fundamental e médio;

- Ausência de modelos de ensino de Libras L1;

- Concepção de língua abordado no curso de Letras Libras nas disciplinas de Libras;

- Será que houve confusão em relação aos conteúdos necessários à formação do professor de Libras versus conteúdos que o aluno precisa ter como usuário da língua para desenvolver a sua competência comunicativa?

Temos, ilustrado na fala de um aluno-estagiário, ao justificar a escolha dos temas gramaticais propostos, um indício de um dos fatores que elencamos.

"considera-se que o conhecimento acerca da estrutura gramatical da lingua de sinais servirá para investigar sobre práticas de ensino de Libras L1" (trecho do projeto do estagiário justificando a escolha de temas gramaticais).

19 A maior parte dos surdos é proveniente de famílias ouvintes que não sabem a língua de sinais. Não sendo possível a esse surdo ter uma aquisição adequada de sua língua materna.

\begin{tabular}{c|c|c|c}
\hline Revista Linguagem em Foco & Fortaleza, CE & v. $12 \mathrm{n} .1$ & ISSN 2674-8266 \\
\hline
\end{tabular}


Essa parece ser uma reflexão para o professor fazer enquanto profissional e pesquisador, e não para uma justificativa de escolha de proposição de temas a serem trabalhados em sala de aula com alunos do ensino fundamental.

O sétimo aspecto foi produção de projetos e relatórios em L2 (Língua Portuguesa). Observamos que dos 45 estagiários surdos do polo da UFC, 42 estagiários optaram em elaborar o relatório de estágio em língua portuguesa, mesmo sendo esta língua a sua segunda língua e, portanto, a língua de menor domínio e a que a impõe mais dificuldades de compreensão e de produção.

Inicialmente, não entendemos essa escolha, uma vez que lhes foi dada a oportunidade de elaboração dos relatórios em Libras, no qual era necessária a produção de um DVD/CD, contendo as mesmas etapas exigidas para a produção do relatório em português; a diferença seria a língua apresentada e o tipo de suporte utilizado, texto sinalizado em mídia e texto impresso, respectivamente. Posteriormente, na análise dos relatórios, nós levantamos hipóteses que podem “justificar” essa escolha. Uma questão levantada e que pode ser muito relevante é a pouca experiência, ou a pouca vivência com gêneros acadêmicos sinalizados, como seria o caso do projeto e relatório de estágio.

\section{CONSIDERAÇÓES FINAIS}

Entendemos que toda experiência pedagógica precisa ser avaliada, principalmente quando se trata de uma experiência pioneira como essa; precisamos pensar o lugar do professor não enquanto repassador de conteúdos, mas enquanto mediador do conhecimento. É necessário pensar além da formação desse profissional que será professor de Libras L1, sendo urgente a elaboração de diretrizes curriculares para o ensino dessa disciplina. Torna-se essencial o levantamento de materiais, conteúdos e estratégias metodológicas desse ensino que vêm sendo trabalhado no país e é urgente a necessidade de produção de materiais didáticos em Libras e a catalogação e registro dos diversos gêneros textuais sinalizados.

\section{REFERÊNCIAS}

ANTUNES, I. Aula de Português: Encontro e interação. São Paulo: Parábola Editorial, 2003.

Língua, texto e ensino: outra escola possível. São Paulo: Parábola Editoria, 2009.

BAKHTIN, M. Os gêneros do discurso. Estática da Criação Verbal. São Paulo, Martins Fontes: 1997.

BASSO, I. M. de S.; STROBEL, K.L.; MASUTTI, M. Metodologia do ensino de Libras L1. Curso de Letras Libras. CCE/UFSC - 2009.

BRASIL. Decreto no 5.626, de 22 de dezembro de 2005. Regulamenta a Lei no 10.436, de 24 de abril de 2002, que dispóe sobre a Língua Brasileira de Sinais - Libras, e o art. 18 da Lei no 10.098, de 19 de dezembro de 2000.

BRASIL. Lei no 10.436 de 24 de Abril de 2002. Dispóe sobre a Língua Brasileira de Sinais - Libras e dá outras providências. 
COSTA, A. N. A e ARAÚJO, J. C. Notícia no jornal escolar: o que sabem os alunos acerca dos gêneros que produzem? In: ARAÚJO, J. C. e DIEB, M. Linguagem e Educaçáo: fios que se entrecruzam na escola. Belo Horizonte: Autêntica, 2007. p. 89 - 99.

LODI, A. C. B.; LUCIANO, R. T. Desenvolvimento da linguagem de crianças surdas em língua brasileira de sinais. In: LODI, A. C. B.; LACERDA, C. B. F. de (orgs). Uma escola, duas línguas: letramentos em língua portuguesa e língua de sinais nas etapas iniciais de escolarização. Porto Alegre: Mediaçáo, 2009.

MACIEL, A. S. N. \& BOMURA, L. S. Formaçáo de professores: presente, passado e futuro. São Paulo: Cortez, 2004.

MARCUSCHI, L. A. Gêneros Textuais: o que são e como se constituem. Recife: UFPE, 2002.

PIMENTA, S. G. O estágio na formação de professores: unidade teoria e prática. 5a Ed. São Paulo: Cortez, 2002.

PIMENTA, S. G. \& LIMA, M. S. L. Estágio e docência. São Paulo, 2004.

POSSENTI, S. Por que (náo) ensinar gramática na escola. São Paulo: Mercado de Letras, 1996.

QUADROS, R. M. de, Alfabeitização e o ensino de língua de sinais. Textura. Canoas, n.3, p. 53-62.

RANGEL, G.; LIMA, S.; SILVA, V. Estágio supervisionado. Curso de Letras Libras CCE/UFSC 2010.

SILVEIRA, H. O currículo de Língua de Sinais e os professores surdos: poder, identidade e cultura surda. In: QUADROS, R de M. e PERLIN, G. Estudos Surdos II. Petropólis, RJ: Arara Azul, 2007. p. 150 189.

STOKOE, W. C. Sign Language Structure. Reedição. Silver Spring-Maryland: Linstok Press, 1960.

TRAVAGLIA, L. C. Gramática e interação: uma proposta para o ensino de gramática no $1^{\circ}$ e $2^{\circ}$ graus. 2a Ed. São Paulo: Cortez, 1997. 